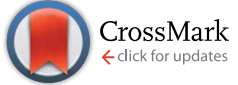

Cite this: RSC Adv., 2015, 5, 82977

\title{
Surface ionic states and structure of titanate nanotubes $\dagger$
}

\author{
Sesha Vempati, ${ }^{* a}$ Fatma Kayaci-Senirmak, ${ }^{\text {ab }}$ Cagla Ozgit-Akgun, ${ }^{\text {ab }}$ Necmi Biyikli $^{\text {ab }}$ \\ and Tamer Uyar*ab
}

Here we present an investigation on $\mathrm{Zn}-\mathrm{Ti}-\mathrm{O}$ ternary (zinc titanate) nanostructures which were prepared by a combination of electrospinning and atomic layer deposition. Depending on the $\mathrm{ZnO}$ and $\mathrm{TiO}_{2} \mathrm{molar}$ ratio, two titanates and one mix phased compound were synthesized by varying the post-annealing temperatures. Specifically $\mathrm{Zn}_{2} \mathrm{TiO}_{4}, \mathrm{ZnTiO}_{3}$ and $\mathrm{ZnO} / \mathrm{TiO}_{2}$ nanostructures were fabricated via thermal treatments $\left(900,700,800{ }^{\circ} \mathrm{C}\right.$, respectively). Structural studies unveiled the titanate phase of the nanostructures. Furthermore, the ionic states of the titanate nanostructures on the surface are revealed to be $\mathrm{Ti}^{3+}$ and $\mathrm{Zn}^{2+}$. Spin-orbit splitting of $\mathrm{Zn} 2 \mathrm{p}$ and Ti2p doublets were, however, not identical for all titanates which vary from 23.09-23.10 eV and 5.67-5.69 eV respectively. Oxygen vacancies were found on the surface of all titanates. The valance band region was analyzed for Zn3d, Ti3p, O2s and O2p and their hybridization, while the edge (below Fermi level) was determined to be at $2.14 \mathrm{eV}, 2.00 \mathrm{eV}$ and 1.99 eV for $\mathrm{Zn}_{2} \mathrm{TiO}_{4}, \mathrm{ZnTiO}_{3}$ and $\mathrm{ZnO} / \mathrm{TiO}_{2}$ respectively.

Received 20th July 2015

Accepted 22nd September 2015

DOI: $10.1039 / \mathrm{c} 5 \mathrm{ra} 14323 \mathrm{c}$

www.rsc.org/advances

\section{Introduction}

Zinc titanates attract a lot of research attention, ${ }^{1-6}$ due to their applicability in microwave dielectrics, catalysts, ${ }^{1}$ pigments, ${ }^{2}$ lubricants ${ }^{6,7}$ and other applications. It should be acknowledged that the formation of titanates takes place through the phase transitions of the $\mathrm{ZnO}-\mathrm{TiO}_{2}$ system which are relatively complex and of course sensitive to the starting materials and preparation methods. ${ }^{1,5}$ For instance, the formation of $\mathrm{ZnTiO}_{3}$ is dependent on the initial phase of $\mathrm{TiO}_{2}$ precursor (anatase $\mathrm{TiO}_{2}$ produces $\mathrm{ZnTiO}_{3}$ ) and grain size (the larger the grain higher the yield). ${ }^{5}$ Some sol-gel methods were established to produce nanoparticles of titanates (see ref. 1 and references therein, and STab 1 of ESI $\dagger$ ). Generally, $\mathrm{ZnO}$ and $\mathrm{TiO}_{2}$ are mixed (ball milled for 24 $\mathrm{h}$ (ref. 4) or $2 \mathrm{~h}$ (ref. 5)) in an appropriate stoichiometry and treated at elevated temperatures. In this context atomic layer deposition (ALD) is a very good choice, where $\mathrm{ZnTiO}_{3}$ can be obtained through sequential deposition of $\mathrm{ZnO}$ and $\mathrm{TiO}_{2}$ followed by a regular thermal treatment. Furthermore, ALD can yield complex architectures down to nanoscale with an excellent compositional control and high homogeneity at molecular level $^{8-12}$ in contrast to conventional solid-state or sol-gel methods which essentially yield powder or thin films. Layer-bylayer formation of ALD can inhibit the secondary phase

${ }^{a}$ UNAM-National Nanotechnology Research Centre, Bilkent University, Ankara, 06800, Turkey. E-mail: svempatio1@qub.ac.uk

${ }^{b}$ Institute of Materials Science \& Nanotechnology, Bilkent University, Ankara, 06800, Turkey.E-mail: uyar@unam.bilkent.edu.tr

$\dagger$ Electronic supplementary information (ESI) available. See DOI: $10.1039 / \mathrm{c} 5 \mathrm{ra} 14323 \mathrm{c}$ formation/segregation during thermal treatments, which is an essential step for the preparation of titanates. Also it can form conformal coatings on complex shapes, high aspect ratio substrates such as nanofibers mats..$^{\mathbf{1 0}, \mathbf{1 3 - 1 5}}$ By considering these factors it would be very beneficial to investigate the structural details and surface chemical nature of nanotubes. Such investigations are vital in the application point of view, for instance, the catalytic activity depends on the conduction band (CB) edge which in case of titanates is constituted mainly by Ti-centred orbitals. Also, coordination of Ti ions and smaller particle size enhance the catalytic activity., ${ }^{1,3}$

In order to prepare the nanotubes, here, first we have prepared nanofibers via electrospinning which act as a template. These nanofibers were subjected to ALD of varying $\mathrm{ZnO}$ and $\mathrm{TiO}_{2}$ molar compositions. These core-shell structured fibers were subjected to calcination at varying, though selected temperatures. This procedure has yielded zinc titanate nanotubes, namely, zinc orthotitanate $\left(\mathrm{Zn}_{2} \mathrm{TiO}_{4}\right)$, zinc metatitanate $\left(\mathrm{ZnTiO}_{3}\right)$ and $\mathrm{ZnO} / \mathrm{TiO}_{2}$. These nanostructures were subjected to a thorough characterization for their crystal structure and surface chemical composition.

\section{Experimental}

\section{Materials}

Formic acid (FA, 98-100\%) was used as a solvent for nylon 6,6. Diethylzinc (DEZn) and tetrakis (dimethylamido) titanium (TDMAT) were procured from Sigma-Aldrich and HPLC-grade deionized (DI) water was used for the ALD process. All the chemicals were used as received from Sigma-Aldrich. 


\section{Electrospinning}

Uniform and bead-free nylon 6,6 nanofibers were produced via electrospinning. The polymer solution consists of $8 \mathrm{wt} \%$ nylon 6,6 in FA. This mixture was stirred for $3 \mathrm{~h}$ at room temperature to obtain a homogeneous and clear solution. This well stirred solution was taken in a syringe fitted with a metallic needle of $\sim 0.8 \mathrm{~mm}$ of inner diameter. Then the syringe with solution was fixed horizontally on a syringe pump (KD Scientific, KDS 101) with a feed rate of $1 \mathrm{~mL} \mathrm{~h}^{-1}$. A $15 \mathrm{kV}$ high voltage is applied (Matsusada, AU Series) between the metal needle and a grounded electrode which was kept at a distance of $\sim 10 \mathrm{~cm}$. Grounded electrode was wrapped with an Al-foil to collect the fibers. The electrospinning process was carried out at $\sim 23{ }^{\circ} \mathrm{C}$ and $36 \%$ relative humidity in an enclosed chamber.

\section{Atomic layer deposition}

Supercycles consisting of $\mathrm{ZnO}$ and $\mathrm{TiO}_{2}$ subcycles were deposited on the nanofibers at $\sim 200{ }^{\circ} \mathrm{C}$ in a Savannah S100 ALD reactor (Cambridge Nanotech Inc.). $\mathrm{N}_{2}$ was used as a carrier gas at a flow rate of $\sim 20 \mathrm{sccm}$. DEZn and $\mathrm{H}_{2} \mathrm{O}$ were used at room temperature, whereas TDMAT was heated to $\sim 75{ }^{\circ} \mathrm{C}$ and stabilized at this temperature for $30 \mathrm{~min}$ prior to the deposition. Depositions were carried out using 'exposure mode' (a trademark of Ultratech/Cambridge Nanotech Inc.) in which dynamic vacuum is switched to static vacuum just before each precursor pulse by closing the valve between the reaction chamber and the pump. This enables the exposure of precursor molecules to the substrate for a certain period of time (i.e., exposure time). This is followed by a purging period, where the chamber is switched back to dynamic vacuum for purging the excess precursors and gaseous byproducts. Three different samples were prepared using 150 supercycles with different $\mathrm{ZnO}: \mathrm{TiO}_{2}$ subcycle ratios; i.e., $1: 2,2: 5$ and $1: 3$. One $\mathrm{ZnO}$ subcycle consists of the following steps: valve $\mathrm{OFF} / \mathrm{H}_{2} \mathrm{O}$ pulse $(0.015 \mathrm{~s}) /$ exposure $(10 \mathrm{~s}) /$ valve $\mathrm{ON} / \mathrm{N}_{2}$ purge $(10 \mathrm{~s}) /$ valve $\mathrm{OFF} / \mathrm{DEZn}$ pulse $\left(\begin{array}{ll}0.015 & \mathrm{~s}\end{array}\right) /$ exposure $(10 \mathrm{~s}) /$ valve $\mathrm{ON} / \mathrm{N}_{2}$ purge $(10 \mathrm{~s})$. One $\mathrm{TiO}_{2}$ subcycle, consists of the following steps: valve $\mathrm{OFF} / \mathrm{H}_{2} \mathrm{O}$ pulse $(0.015 \mathrm{~s}) /$ exposure $(10 \mathrm{~s}) /$ valve $\mathrm{ON} / \mathrm{N}_{2}$ purge $(10 \mathrm{~s}) /$ valve OFF/TDMAT pulse $(0.1 \mathrm{~s})$ /exposure $(10 \mathrm{~s}) /$ valve $\mathrm{ON} / \mathrm{N}_{2}$ purge $(10 \mathrm{~s})$.

\section{Calcination}

Samples of ratios $1: 2,2: 5$ and $1: 3$ were subjected to calcination at $900{ }^{\circ} \mathrm{C}\left(\mathrm{Zn}_{2} \mathrm{TiO}_{4}, \mathrm{ZT} 14\right), 700{ }^{\circ} \mathrm{C}\left(\mathrm{ZnTiO}_{3}, \mathrm{ZT} 13\right)$ and 800 ${ }^{\circ} \mathrm{C}\left(\mathrm{ZnO} / \mathrm{TiO}_{2}, \mathrm{ZT} 12\right)$, respectively. These samples will be referred as abbreviated in the parenthesis.

\section{Characterization}

The morphologies of the samples were investigated using a Scanning Electron Microscope (SEM, FEI-Quanta 200 FEG). A nominal $5 \mathrm{~nm} \mathrm{Au/Pd}$ alloy was sputtered onto the samples prior to the observation under SEM. Also transmission electron microscope (TEM, FEI-Tecnai G2 F30) was employed. For TEM imaging, the samples were dispersed in ethanol and the suspension was collected onto a holey carbon coated TEM grid. $\mathrm{X}$-ray diffraction $(\mathrm{XRD})$ patterns were recorded $\left(2 \theta=20^{\circ}-80^{\circ}\right)$ by employing PANalytical X'Pert Multi Purpose X-ray diffractometer with $\mathrm{CuK} \alpha$ radiation $(\lambda=1.5418 \AA)$. The ionic state of the surface elements were determined via X-ray photoelectron spectroscopy (XPS, Thermo Scientific, K-Alpha, monochromatic AlK $\alpha$ X-ray source, $400 \mu \mathrm{m}$ spot size, $h \nu=1486.6 \mathrm{eV}$ ) in the presence of a flood gun charge neutralizer. For the core-level spectra, pass energy and step size were $30 \mathrm{eV}$ and $0.1 \mathrm{eV}$, respectively. Peak deconvolutions of the XPS spectra were performed through Avantage software.

\section{Results and discussion}

Schematic diagram of various steps involved to fabricate the nanotubes is shown in Fig. 1. Initially polymer nanofibers were produced via electrospinning which were then subjected to ALD of $\mathrm{ZnO}$ and $\mathrm{TiO}_{2}$ subcycles of varying $\mathrm{ZnO}$ and $\mathrm{TiO}_{2}$ content. These core-shell nanofibers were subjected to thermal treatment at 900,700 or $800{ }^{\circ} \mathrm{C}$ yielding three types of nanostructures. i.e. (a) electrospun polymer nanofiber + ALD yields core-shell structure, (b) calcination of (a) at a suitable temperature removes the core polymer and the inorganic coating takes the nanotube form and (c) depending on the calcination temperature a severe reorganization of the crystal structure takes place, then the nanotube structure may collapse yielding grainy fibrous structure.

The representative SEM images of as deposited and calcined samples are shown in Fig. 2. The first impression is that the ALD did not cause any deterioration to the polymer nanofibers. After calcination apart from the changes in the crystallinity, morphological changes can be expected ${ }^{\mathbf{1 5 , 1 6}}$ which is in contrast

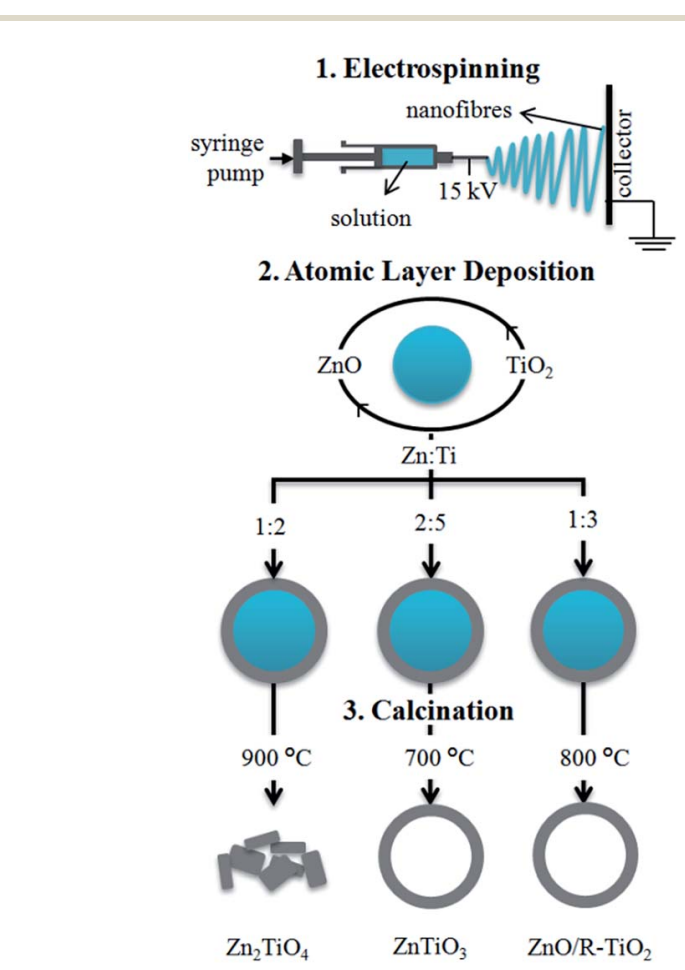

Fig. 1 Schematic diagram depicting electrospinning, ALD and calcination. 


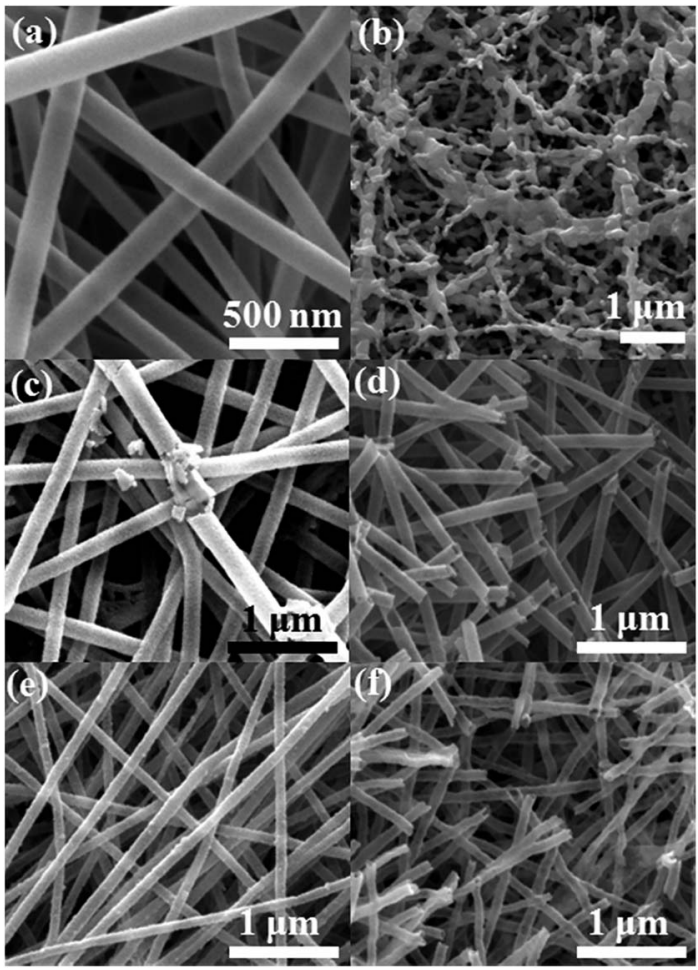

Fig. 2 SEM images of nanotube titanates ( $a$ and b) ZT14, ( $c$ and d) ZT13 and (e and f) ZT12

to the removal of core by washing. ${ }^{8}$ From Fig. $2 \mathrm{a}$ and $\mathrm{b}$ these changes are significant and explicit in the case of ZT14 samples which were calcined at $900{ }^{\circ} \mathrm{C}$, where nanotubes are generally expected. In stark contrast, the morphology is completely altered and nanotubes were not seen nevertheless, we can see the traces of fibrous structure with grains. The average diameter and length were $135 \pm 12 \mathrm{~nm}, 175 \pm 5 \mathrm{~nm}$ and the distributions of which are shown in SFig. 1a and b of ESI, $\dagger$ respectively. The average fiber diameter is about $\sim 90 \mathrm{~nm}$. It appears to be the case that the average diameter of the fiber determines the width of the crystallites while the length is stimulated by the thermodynamics and mobility of the atoms (ions) at high temperature. This excessively high temperature, although required for crystallization, has caused a complete restructuring of the morphology. Since the dielectric properties and the grain size are interconnected ${ }^{17}$ the present results are quite interesting as the average diameter of the fiber can be controlled by appropriate choice of the polymer and solvent combination. ${ }^{10,18}$ Furthermore, relatively higher diameter $(0.5-2 \mu \mathrm{m})$ can be achieved by selecting non-polymeric system for electrospinning, ${ }^{8}$ which is proven to be compatible in ALD. ${ }^{8}$ Notably the uniformity in the grain size reduces the additional dielectric loss. ${ }^{17}$ Nevertheless, in XRD we will see the formation of a well developed polycrystalline $\mathrm{Zn}_{2} \mathrm{TiO}_{4}$. On the other hand, since the ZT13 (Fig. 2c and d) and ZT12 (Fig. 2e and f) samples were derived from the calcination at relatively lower temperature, a stark contrast in the morphology is apparent. For these samples a nanotube-like structure is evidenced after calcination. To emphasize these samples are similar to those when the core region is subjected washing ${ }^{8}$ while keeping aside the changes in the crystallinity due to thermal treatment. It is interesting to note that the nanotubes are thin enough to be electron transparent (Fig. 2d and f) where the bottom layer is visible.

TEM images of titanate samples are shown Fig. 3. SEM images of ZT14 have shown a grainy structure, where the expected tubular morphology is lost during the relatively high temperature calcination (Fig. 2b). Hence local crystal structure analysis on ZT14 sample has evidenced well developed crystalline regions (Fig. 3a and b). The fast Fourier transform (FFT) image of Fig. 3a suggested a single crystalline grain, see insert. Fig. $3 \mathrm{~b}$ suggests a grain boundary region (see the annotations (i) and (ii) on Fig. 3b). It is interesting to note that majorly region (i) is polycrystalline in contrast to single crystalline region (ii). We will see a polycrystalline nature (XRD) which averages a large sample unlike TEM. It is generally assumed that the grain boundary region is less crystalline than either of the mating parts. However, this is not the case as we can explicitly see a crystalline grain boundary which obviously is an effect of high temperature calcination. The thickness of the ALD coating is estimated from the TEM images of ZT13 nanotubes and annotated on the Fig. 3c and d. ZT13 nanotubes consists of a well developed and uniform sized crystal grains, however the tube like structure sustained its integrity. Furthermore, the diameter of the polymeric nanofiber template plays an important role in the integrity of the tube with respect to grain size. ${ }^{8}$ As

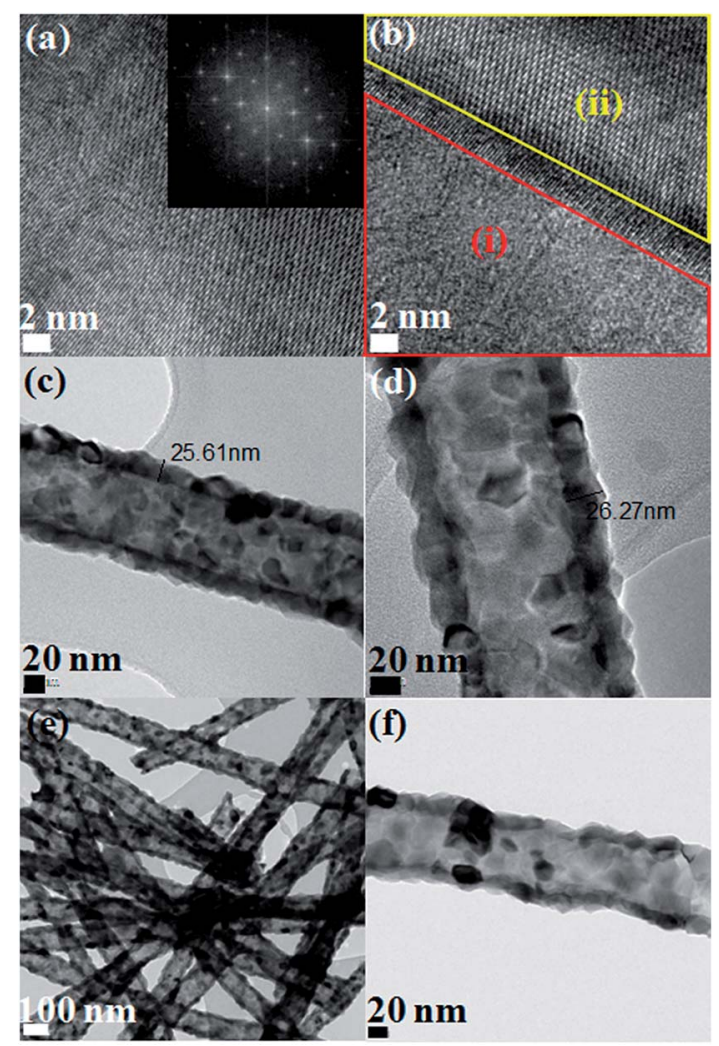

Fig. 3 TEM images of nanotube titanates ( $a$ and b) ZT14, (c and d) ZT13 and (e and f) ZT12. Insert of (a) depicts the FFT image of (a) indicating the single crystalline nature. 
mentioned earlier, the uniformity in the grain size is an important character for dielectric properties. ${ }^{17}$ ZT12 sample depicted similar character to that of ZT13 sample in terms of grain size uniformity and tube-like structure (Fig. 3e and f).

In Fig. 4 we have plotted XRD patterns from ZT14, ZT13 and ZT12 samples along with the reflections identified. In the case of ZT14, it is predominantly cubic $(c)$ phased $\mathrm{Zn}_{2} \mathrm{TiO}_{4}$. When the calcination temperature decreased to $700{ }^{\circ} \mathrm{C}$ for $\mathrm{ZnO}$ and $\mathrm{TiO}_{2}$ ratio of $1: 2$ hexagonal $(h)$ phased $\mathrm{ZnTiO}_{3}$ emerged (ZT13). For ZT12 sample we can see the reflections from $\mathrm{ZnO}$ and rutile $\mathrm{TiO}_{2}\left(\mathrm{R}-\mathrm{TiO}_{2}\right)$ where the calcination temperature is about $800{ }^{\circ} \mathrm{C}$. For this molar ratio, earlier ${ }^{19}$ when the calcination temperature increased to $800{ }^{\circ} \mathrm{C}, h-\mathrm{ZnTiO}_{3}$ and $c$ - $\mathrm{ZnTiO}_{3}$ were the dominant phases. Only trace amount of the $\mathrm{R}^{-\mathrm{TiO}_{2}}$ was found. ${ }^{19}$ However, in the present context it is notable that for calcination temperatures such as 800 to $900{ }^{\circ} \mathrm{C}$, the $h-\mathrm{ZnTiO}_{3}$ is not the dominant phase. At higher temperature the decomposition of $h-\mathrm{ZnTiO}_{3}$ into cubic spine $\left(c-\mathrm{Zn}_{2} \mathrm{TiO}_{4}\right)$ and $\mathrm{R}-\mathrm{TiO}_{2}$ is possible ${ }^{1,20}$ and the peaks related to $c-\mathrm{Zn}_{2} \mathrm{TiO}_{4}$ (JCPDS Card no. 25-1164) and $\mathrm{R}-\mathrm{TiO}_{2}$ appeared. For a sample that is treated at $800{ }^{\circ} \mathrm{C}$ has shown diffraction pattern of $\mathrm{ZnO}$ and $\mathrm{R}-\mathrm{TiO}_{2}$. For the case of $h-\mathrm{ZnTiO}_{3},(104)$ and (110) reflections have depicted intensity levels which are the highest and the next highest. Preferential (104) growth orientation is attributed to the reduction in the free energy in reaching a stable growth state. The stable growth state is closed packed plane with lowest surface energy (SE). This is well supported by previous DFT simulations studies. (104) and (110) reflections have shown unrelaxed $\mathrm{SE}$ of 5.01 and $5.16 \mathrm{~J} \mathrm{~m}^{-2}$ respectively. This SE is decreased $\sim 18 \%$ upon relaxation which is a considerable quantity. ${ }^{6}$ Furthermore, the FWHM of (104) is about $2 \theta=$ $\sim 0.188^{\circ}$ in the present case. In a previous study ALD grown film ${ }^{6}$ has shown relatively higher fwhm of $\sim 1.7^{\circ}(2 \theta)$ which is attributed to growth disorder/defects. i.e. nonuniform strain and/or dislocations, stacking faults and high angle grain boundaries. For instance, stacking faults can be referred to those persist on (104) plane $^{6}$ Furthermore, these films ${ }^{6}$ have depicted condensation of oxygen vacancies $\left(V_{\mathrm{O}} \mathrm{s}\right)(\mathrm{Zn}: \mathrm{Ti}: \mathrm{O}$ : $1: 1: 2.7)$ which influences the (104) plane severely such as planar stacking faults, ${ }^{6}$ i.e. disappearing or introducing an extra

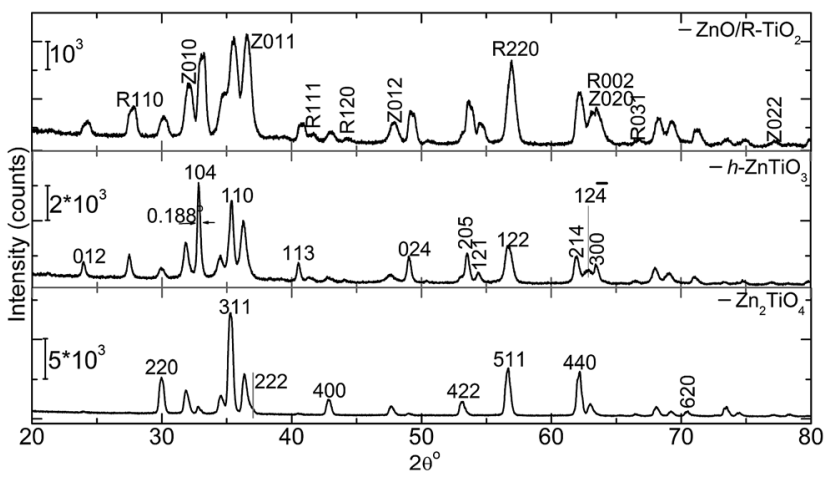

Fig. 4 XRD patterns of nanotube titanates ZT14, ZT13 and ZT12. For $\mathrm{ZnO} / \mathrm{R}-\mathrm{TiO}_{2}$ additional planes (104), (110), (113) and (121) from $h$ $\mathrm{ZnTiO}_{3}$ phase were not annotated.
(104) plane. Previously, ${ }^{7}$ a thin film of $\mathrm{ZnTiO}_{3}$ (ilmenite) depicted only (104) and (12) $)$ reflections at $2 \theta=\sim 33.1^{\circ}(2.7 \AA)$ and $\sim 62.1^{\circ}(1.5 \AA)$ respectively. In the present case, these reflections appeared at $32.87^{\circ}, 62.96^{\circ}$, respectively. This difference can be attributed to the strain due to the nanotube structure, however, note that ref. 7 employs ALD for the synthesis.

Survey XP spectra for the three compounds are shown in SFig. $2 \dagger$ including atomic percentages. The results suggest that the composition of constituting elements is consistent with the chemical formula. However, other phases should be taken into account as we have seen diffraction peaks corresponding to $\mathrm{ZnO}$ and $\mathrm{R}^{-} \mathrm{TiO}_{2}$ phases (Fig. 4). Carbon contamination might have been occurred during the calcination in ambient atmosphere and subsequent transfer of samples into the XPS-analyses chamber. Core-level Zn2p spectra indicated a doublet, $2 \mathrm{p}_{3 / 2}$ and $2 \mathrm{p}_{1 / 2}$ at $\sim 1021.5$ and $\sim 1044.5 \mathrm{eV}$, respectively, which indicates +2 state of $\mathrm{Zn}$. Also two satellite peaks were noticed in the process of deconvolution, however, they were not shown in Fig. 5. The spin-orbit splitting $(\Delta E)$ is $\sim 23.1 \mathrm{eV}$ which is consistent with the literature ${ }^{\mathbf{2 1}}$ however the variation can be attributed to the differences in the ionic or covalent environments on the surface. O1s spectra depicted two chemically different environments where the major contribution was due to the lattice oxygen $(530.01 \mathrm{eV}) .{ }^{15,21}$ The other oxygen contribution can be attributed to chemisorbed oxygen $\left(\mathrm{O}_{\mathrm{Ch}}\right) . \mathrm{O}_{\mathrm{Ch}}$ appeared at $531.6 \mathrm{eV}$ indicated incorporation of $-\mathrm{OH},-\mathrm{CO}$, adsorbed $\mathrm{H}_{2} \mathrm{O}$ and/or $\mathrm{O}_{2}$ or $\mathrm{O}^{-}$and $\mathrm{O}^{2-}$ ions ${ }^{21,22}$ essentially

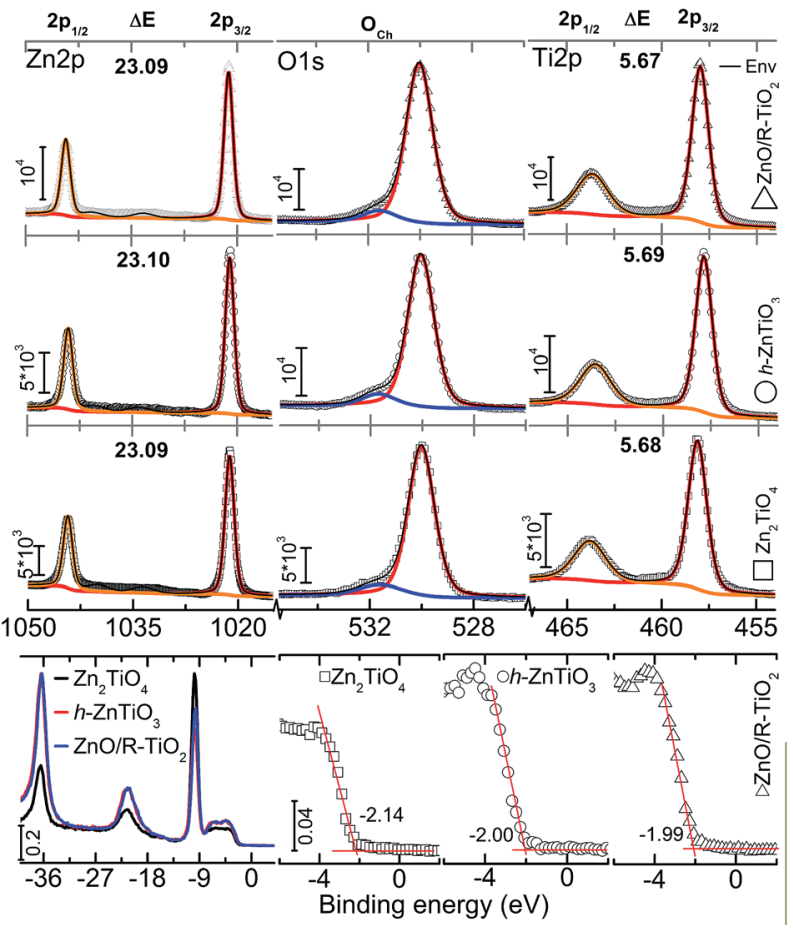

Fig. 5 XP spectra of ZT14, ZT13 and ZT12 samples. In the deconvolution of Zn2p two satellite peaks were present, however, they were hidden in the figure for brevity. $0 \mathrm{eV}$ on energy scale indicate the Fermi level. 
occupying the $V_{\mathrm{O}} \mathrm{S}$. These defects play a critical role in the emission properties and related applications. ${ }^{\mathbf{1 0 1 5 , 2 2}}$ The $\mathrm{O}_{\mathrm{Ch}}$ fractions were 9.76, 8.88 and 7.67\% for ZT14, ZT13 and ZT12, respectively.

Ti2p spectra indicated a single chemical environment in contrast to the samples synthesized by sol-gel technique ${ }^{1}$ where Ti2p depicted two chemical environments for $\mathrm{ZnTiO}_{3}$. The second chemical environment in ref. 1 is attributed to Ti ions on the external surface of $\mathrm{TiO}_{2}$ that are partly four or fivecoordinated, for particles with size less than $20 \mathrm{~nm}$. Different reactivities and surface properties are expected from these unsaturated coordination. ${ }^{23}$ In the case of $\mathrm{TiO}_{2}$, the $\Delta E$ between $2 \mathrm{p}_{3 / 2}$ and $2 \mathrm{p}_{1 / 2}$ is $\sim 6.2 \mathrm{eV}$, where the peaks are at 458.50 and $464.70 \mathrm{eV}$, respectively. The $\Delta E$ for all the samples is $\sim 5.7 \mathrm{eV}$ and attributed to octahedral coordination $\left(\mathrm{Ti}^{3+}\right)$, although we have seen some XRD reflections corresponding to $\mathrm{R}-\mathrm{TiO}_{2}$. Investigation on local atomic structure has indicated $\mathrm{ZnTiO}_{3}$ and $\mathrm{Zn}_{2} \mathrm{TiO}_{4}$ have six coordinated $\mathrm{Ti}^{4+}$ ions. ${ }^{4}$

Valance band (VB) region with normalized intensity is shown in Fig. 5 (bottom). Zn3d is relatively more intense than Ti3p for $\mathrm{Zn}_{2} \mathrm{TiO}_{4}$ while the converse is true for $h-\mathrm{ZnTiO}_{3}$ and $\mathrm{ZnO} / \mathrm{R}-\mathrm{TiO}_{2}$ cases. A closure inspection of $\mathrm{VB}$ region indicated onset values of $-2.14,-2.00$ and $-1.99 \mathrm{eV}$ for $c-\mathrm{Zn}_{2} \mathrm{TiO}_{4}, h$ $\mathrm{ZnTiO}_{3}$ and $\mathrm{ZnO} / \mathrm{R}-\mathrm{TiO}_{2}$ respectively (Fig. $5 \mathrm{~b}$ bottom right). Upper part of the core-state $(-19$ to $-17.3 \mathrm{eV})$ is occupied by O2s electrons. ${ }^{21}$ The VB consists of $\mathrm{Zn} 3 \mathrm{~d}, \mathrm{O} 2 \mathrm{p}$ and Ti3d states. $\mathrm{Zn} 3 \mathrm{~d}$ state is localized at $-5.7 \mathrm{eV}$, while $\mathrm{O} 2 \mathrm{p}$ and Ti3d states hybridize in the range $-5 \mathrm{eV}$ to Fermi level $(0 \mathrm{eV}$ on the energy scale). However, as we noted earlier, the VB edge slightly differs among the samples which is attributed to the variations in the hybridization of the corresponding orbitals. The results are qualitatively similar to experimental studies on mixed cubic/hexagonal phase of the compound. ${ }^{24}$ To further comment on the band structure, CB composed of Ti3d orbitals. A computed and experimental bandgap of $\sim 3.18 \mathrm{eV}$ [ref. 3] and $\sim 3.1 \mathrm{eV}$ [ref. 25] are evidenced for $\mathrm{Zn}_{2} \mathrm{TiO}_{4}$, respectively. However, apparently, in the case of spinal structures bandgap values depend on the (dis)ordering of the cations at octahedral sites. This essentially implies that the final gap values are strongly influenced by the details of preparation.

\section{Conclusions}

Zinc titanate nanotubes were prepared by a combination of electrospinning and ALD followed by a high temperature thermal treatment. The crystal structure confirmed the phase formation of $c-\mathrm{Zn}_{2} \mathrm{TiO}_{4}, h-\mathrm{ZnTiO}_{3}$ and mixed phase $\mathrm{ZnO} / \mathrm{R}-\mathrm{TiO}_{2}$. The surface chemical nature of the transition metal ions were determined to be $\mathrm{Ti}^{3+}$ and $\mathrm{Zn}^{2+}$. Furthermore $V_{\mathrm{O}}$ S were detected on the surface, however, with varying $\mathrm{O}_{\mathrm{Ch}}$ content of 7.679.76\%. $\Delta E$ of $\mathrm{Zn} 2 \mathrm{p}$ and Ti2p doublets was consistent with the literature, while the slight differences are attributed to the environmental effects. The VB edges are determined to be at $2.14 \mathrm{eV}, 2.00 \mathrm{eV}$ and $1.99 \mathrm{eV}$ (below Fermi level) for $\mathrm{Zn}_{2} \mathrm{TiO}_{4}$, $\mathrm{ZnTiO}_{3}$ and $\mathrm{ZnO} / \mathrm{R}-\mathrm{TiO}_{2}$ respectively. This study enhances the understanding of the fundamentally important surface chemical nature of titanate nanotubes in addition to the applicability of this process.

\section{Acknowledgements}

S. V. thanks TUBITAK (TUBITAK-BIDEB 2221-Fellowships for Visiting Scientists and Scientists on Sabbatical) for the postdoctoral fellowship. F. K.-S. thanks TUBITAK-BIDEB for a PhD scholarship. N. B. thanks EU FP7-Marie Curie-IRG for funding NEMSmart (PIRG05-GA-2009-249196). T. U. thanks EU FP7Marie Curie-IRG (NANOWEB, PIRG06-GA-2009-256428) and The Turkish Academy of Sciences - Outstanding Young Scientists Award Program (TUBA-GEBIP) for partial funding. Authors thank M. Guler for technical support for TEM analysis. Authors also thank Dr Z. Ali, Materials Modeling Center, Department of Physics, University of Malakand, Chakdara, Pakistan for providing the computational data of $\mathrm{VB}$ and $\mathrm{CB}$ for $h-\mathrm{ZnTiO}_{2}$ and $\mathrm{Zn}_{2} \mathrm{TiO}_{4}$.

\section{Notes and references}

1 Y. Wang, P.-H. Yuan, C.-M. Fan, Y. Wang, G.-Y. Ding and Y.-F. Wang, Ceram. Int., 2012, 38, 4173-4180.

2 A. T. McCord and H. F. Saunder, US Pat., 2379019, 1945.

3 Z. Ali, S. Ali, I. Ahmad, I. Khan and H. A. R. Aliabad, Phys. B, 2013, 420, 54-57.

4 G. Akgul, J. Mol. Struct., 2013, 1037, 35-39.

5 Z. Liu, D. Zhou, S. Gong and H. Li, J. Alloys Compd., 2009, 475, 840-845.

6 W. Sun, A. Ageh, H. Mohseni, T. W. Scharf and J. Du, Appl. Phys. Lett., 2014, 104, 241903.

7 V. Ageh, H. Mohseni and T. W. Scharf, Surf. Coat. Technol., 2014, 241, 112.

8 A. Celebioglu, S. Vempati, C. O. Akgun, N. Biyikli and T. Uyar, RSC Adv., 2014, 4, 61698.

9 C. O. Akgun, F. Kayaci, S. Vempati, A. Haider, A. Celebioglu, E. Goldenberg, S. Kizir, T. Uyar and N. Biyikli, J. Mater. Chem. C, 2015, 3, 5199.

10 F. Kayaci, S. Vempati, C. O. Akgun, I. Donmez, N. Biyikli and T. Uyar, Appl. Catal., B, 2015, 176-177, 646-653.

11 C. O. Akgun, F. Kayaci, I. Donmez, T. Uyar and N. Biyikli, J. Am. Ceram. Soc., 2013, 96, 916-922.

12 C. O. Akgun, I. Donmez and N. Biyikli, ECS Trans., 2013, 58, 289-297.

13 P. Heikkilä, T. Hirvikorpi, H. Hilden, J. Sievänen, L. Hyvärinen, A. Harlin and M. Vähä-Nissi, J. Mater. Sci., 2012, 47, 3607-3612.

14 E. Santala, M. Kemmel, M. Leskela and M. Ritala, Nanotechnology, 2009, 20, 035602.

15 F. Kayaci, S. Vempati, C. Ozgit, I. Donmez, N. Biyikli and T. Uyar, Nanoscale, 2014, 6, 5735.

16 F. Kayaci, S. Vempati, C. O. Akgun, N. Biyikli and T. Uyar, Appl. Catal., B, 2014, 156-157, 173-183.

17 R. K. Sirugudu, R. K. M. Vemuri, S. Venkatachalam, A. Gopalakrishnan and S. M. Budaraju, Journal of Microwave Power and Electromagnetic Energy, 2011, 45, 128136. 
18 F. Kayaci, C. O. Akgun, I. Donmez, N. Biyikli and T. Uyar, ACS Appl. Mater. Interfaces, 2012, 4, 6185-6194.

19 J. Z. Kong, A. D. Li, H. F. Zhai, H. Li, Q. Y. Yan, J. Ma and D. Wu, J. Hazard. Mater., 2009, 171, 918-923.

20 M. R. Mohammadi and D. J. Fray, J. Eur. Ceram. Soc., 2010, 947-961.

21 A. V. Naumkin, A. K. Vass, S. W. Gaarenstroom and C. J. Powell, Journal, NIST Standard Reference Database 20, Version 4.1, 2012.
22 F. Kayaci, S. Vempati, I. Donmez, N. Biyikli and T. Uyar, Nanoscale, 2014, 6, 10224-10234.

23 T. Rajh, J. M. Nedeljkovic, L. X. Chen, O. Poluektov and M. C. Thurnauer, J. Phys. Chem. B, 1999, 103, 3515-3519.

24 P. K. Jain, D. Kumar, A. Kumar and D. Kaur, J. Optoelectron. Adv. Mater., 2010, 4, 299.

25 P. H. Borse, C. R. Cho, K. T. Lim, T. E. Hong, E. D. Jeong, J. H. Yoon, S. M. Yu and H. G. Kim, J. Ceram. Process. Res., 2012, 13, 42-46. 